\title{
ASPECTOS QUE BUSCAM NORTEAR AS AÇÕES DAS SECRETARIAS EM TORNO DO CUIDADO COM OS CUIDADORES: DESAFIOS E POLITICAS PÚBLICAS
}

Drágsa Silva Santos Lima1

\begin{abstract}
RESUMO
O presente estudo tem como objetivo principal, analisar a inexistência de politicas públicas em relação à falta de cuidados com a saúde dos profissionais de Saúde e Educação, tendo como premissa, dialogar sobre os desafios da educação escolar, saúde e politicas públicas da educação básica e saúde. Percebe-se que mesmo assegurado em lei o direito de ser cuidado, os gestores não se movem em torno de garantir a efetivação do cuidado na prática dentro das instituições públicas e nesse clina é nitida a falta de articulação dos gestados em torno de conhecer seus direitos e exigir que sejam colocados em prática. Portanto, essa luta de cuidar do cuidador é ausente no dia a dia dos trabalhadores (a) que se apresenta desde o chefe imediato até o gestor de curvatura mais elevada, que divergem pela formação a falta de intersse. Desse modo, conclui-se que os obstaculos devem ser vencidos atraves da dialogicidade entre os gestores, gestados e a ciência, e a criação de Políticas Públicas que auxiliem na promoção da saúde de qualidade dos profissionais da educação e saúde. $O$ estudo orientou-se pela pesquisa qualitativa: observação, análise documental, além das pesquisas bibliográficas exploratórias, que aborda discussões ancoradas em leis brasileitas pertinentes ao tema, estudos contemporaneos e diversos, com propostas de discurssões entre gestores e gestados, dialogando com renomados autores como: Aranha (2006), Benevides e Passos, (2005) e Pereira e Hannas (2000).
\end{abstract}

Palavras-Chave: Desafios; Cuidado; Educação Escolar; Saúde; Politicas Públicas.

\section{ABSTRACT}

The present study has as main objective, to analyze the lack of public policies in relation to the lack of health care of the Health and Education professionals, having as premise, to dialogue about the challenges of school education, health and public policies of basic education and health. It is noticed that even though the right to be cared for is guaranteed by law, managers do not move around to guarantee the effectiveness of care in practice within public institutions and in this cline, the lack of articulation of pregnant women around knowing their rights is clear. and demand that they be put into practice. Therefore, this struggle to take care of the caregiver is absent in the daily lives of workers (a) who present themselves from the immediate boss to the manager with the highest curvature, who differ due to the lack of intersection. Thus,

\footnotetext{
1 É Mestra em Ciências da Educação pela Faculdade Interamericana de Ciências Sociales (FICS). Possui Graduação em Pedagogia pela Universidade do Estado da Bahia. É licenciada em Ciências Biológicas pela FAVED. É Especialista em Gestão e Orientação Educacional pela Faculdade Darwin de Brasília; e em Ciências da Educação pela Faculdade Afirmativo. É professora da educação básica do município de Serra do Ramalho, Estado da Bahia. E - mail: dragsasantos@gmail.com
} 
it is concluded that obstacles must be overcome through the dialog between managers, pregnant women and science, and the creation of Public Policies that assist in the promotion of quality health for education and health professionals. The study was guided by qualitative research: observation, documentary analysis, in addition to exploratory bibliographic research, which addresses discussions anchored in Brazilian laws relevant to the theme, contemporary and diverse studies, with proposals for discussions between managers and pregnant women, dialoguing with renowned authors such as: Aranha (2006), Benevides e Passos, (2005) and Pereira and Hannas (2000).

Keywords: Challenges. Caution. Schooling. Health. Public policy.

\section{RESUMEN}

El presente estudio tiene como objetivo principal, analizar la falta de políticas públicas en relación a la falta de atención a la salud de los profesionales de la Salud y la Educación, teniendo como premisa, dialogar sobre los desafíos de la educación escolar, la salud y las políticas públicas de educación básica. y salud. Se advierte que a pesar de que el derecho a ser atendido está garantizado por la ley, los gerentes no se mueven para garantizar la efectividad de la atención en la práctica dentro de las instituciones públicas y en esta línea, la falta de articulación de las gestantes en torno al conocimiento de sus derechos se ve afectada. claro. y exigir que se pongan en práctica. Por lo tanto, esta lucha por cuidar al cuidador está ausente en la vida cotidiana de los trabajadores (a) que se presentan del jefe inmediato al gerente con la mayor curvatura, que se diferencia por la falta de intersección. Así, se concluye que los obstáculos deben ser superados a través del diálogo entre gestores, gestantes y ciencia, y la creación de Políticas Públicas que coadyuven en la promoción de la salud de calidad para la educación y los profesionales de la salud. El estudio fue guiado por la investigación cualitativa: observación, análisis documental, además de la investigación bibliográfica exploratoria, que aborda discusiones ancladas en leyes brasileñas relevantes al tema, estudios contemporáneos y diversos, con propuestas de discusión entre gerentes y gestantes, dialogando con reconocidos autores como: Aranha (2006), Benevides e Passos, (2005) y Pereira y Hannas (2000).

Palabras clave: Desafíos. Precaución. Enseñanza. Salud. Política pública. 


\section{INTRODUÇÃO}

O presente estudo, tem como objetivo de estudo principal, analisar a inexistência de politicas públicas em relação à falta de cuidados com a saúde dos profissionais de Saúde e Educação. Assim, o trabalho tem a finalidade de apresentar os aspectos que nortearam as ações pedagógicas, através das secretarias, estabelecidas pela pesquisa de campo nas fases de observação, realizada nas secretarias de saúde e educação do município de Bom Jesus da Lapa, estado da Bahia.

Desta forma, o estudo apresentado, busca abordar no que se refere a falta de cuidado e atenção com a saúde dos profissionais de saúde e educação do município de Bom Jesus da Lapa. Portanto, o cuidado com a saude desses profissionais, visa gerar transformação de caráter prático, no contexto de valorização da saúde do trabalhador em saúde e educação, bem como a subtração e redução de trabalhadores doentes. Uma aspiração que será compartilhada com a gestão e que trará muitas benfeitorias.

Por outro lado, propõe-se a implantação de políticas públicas voltadas para ações que visam estar Cuidando dos Cuidadores com a finalidade de preencher uma enorme lacuna na área da saúde e educação: o cuidado com quem dedica a sua vida cuidando de outros. Observa-se que possui também a necessidade de receber cuidados e atenção especiais, portanto, deve ser garantido a eles o acesso à assistência à saúde em todos os níveis de complexidade com qualidade de atendimento, em ambiente favorável, tendo como fruto a valorização e cuidado com a saúde dos profissionais de saúde.

Justifica-se a pesquisa, pela necessidade de conhecer as perspectivas dos profissionais de saúde e educação e a contribuição destes em sua prática profissional para o bem comum de todos. Assim sendo, a pesquisa parte da hipótese de que os profissionais da Saúde e educação, representam uma das maiores categorias do município, portanto, ao prestar um serviço de excelente qualidade, uma vez que gozam de assistência necessária à saúde pessoal, trará benefícios aos usuários e a população e consequentemente ao município, contribuindo com seu desenvolvimento de bem-estar social.

Portanto, a pesquisa busca responder de que maneira a inexistência de politicas públicas em relação à falta de cuidados com a saúde dos profissionais de 
Saúde e Educação pode afetar a vida desse? O que motivou a pesquisar e a responder esta indagação foi o fato de entender que a saúde é uma excelente ferramenta para o profissional uma vez que se encontra na posição de cuidador, além de ser um direito.

A motivação para a realização do estudo centrou-se na percepção de que os profissionais que atuam na saúde e educação, são de suma importância para o desenvolvimento da sociedade de maneira sadia.

O estudo orientou-se pela pesquisa qualitativa: observação, análise documental, além das pesquisas bibliográficas exploratórias com base em pressupostos teóricos de autores renomeáveis como: Aranha (2006), Benevides e Passos, (2005) e Pereira e Hannas (2000) dentre outros e com base nos fundamentos apresentados para o desenvolvimento de uma interpretação pessoal, estudos contemporaneos e diversos, com propostas de discurssões entre gestores e gestados, dialogando com renomados autores.

\section{A IMPORTÂNCIA DAS AÇÕES DAS SECRETARIAS DE SAÚDE E EDUCAÇÃO EM TORNO DO CUIDADO COM OS CUIDADORES}

Em um mundo tão diverso, complexo o qual estamos ineridos, versar sobre os trabalhadores e trabalhadoras da saúde e educação é desafiador, porém, gratificando devido a importancia de ambas categorias que são as miores do mundo, serem muito importantes para o desenvolvimento da humanidade como um todo.

Com essa afirmativa, percebe-se que a caminhada é longa e ardua, porém, não se pode desanimar bem menos dessistir, porque sabemos que a educação sem sombra de duvidas é o melhor caminho para dicipar todos os entraves impostos pela sociedade em relação a falta de valorização desses profisionais que dão o melho de si diunturnamente, para obtermos uma sociedade justa, igualitária e sem repressões, proporcionando a cada individuo a chance de ser um ser ativo que se preocupa com o mundo em que vivemos e dê sua parcela de contribuição para a construção de uma postura melhor, em especial quando se tratar de liderança, ou seja, cuidar de pessoas coletivamente, que significa responsabilidade multiplicada, bem como, resultados.

Dessa forma, os eixos de intervenção da política de saúde se firmam, ao longo dos tempos, na promoção e prevenção, tendo claro que saúde não é ausência de doença e sim qualidade de vida. 
De tal modo, é indispensável na promoção da vida, da saúde e manutenção da espécie. Por isso ser tão importante o cuidade com a educação e a saúde. A educação por sua vez não pode se caracteriza apenas como o meio pelo qual determine instrução ao individuo, assim é pertinente destacar Brandão (1995) quando nos afirma que

De acordo com as ideias de alguns filósofos e educadores, a educação é um meio pelo qual o homem desenvolve potencialidades biopsíquicas inatas, mas que não atingiriam a sua perfeição sem a aprendizagem realizada através da educação (BRANDÃO, 1995, p. 61).

Diante desse contexto, a luta dos tabalhadores da saúde e educação, pela garantia de seus direitos retrata a necessidade de uma educação que no bojo de sua construção tenham a participação dos envolvidos para que possam contemplar suas vivencias e desafios, bem como, suas conquista e anceios, afim de que seja uma educação universalizada e que possa ser trabalhada com os estudantes desde cedo, desse modo, conquistar o respeito desde então, para que possam ser multiplicadores e futuros cidadão que cresçam cultivando o habito de pensar, com um olhar respeitoso sobre os trabalhadores e trabalhadoras de saúde e educação.

Olhar esse que possa contrapor ao modelo contemporaneamente vivenciado, e transforme seu palco de lutas e resistencias em elevadas conquistas em torno das instituições publicas e privadas de educação e saúde, de modo formal, normatizado e repassado as atuais e novas gerações. Segundo Matos e Mugitti (p.23); "O ter que agir traz consigo, também, a movimentação de novas práticas, novas posturas que, porconseguinte, desmendam, novos conhecimentos. O agir significa, acima de tudo, se expor, estar em evidência, ser observado e julgado".

Para tanto, pode-se afirmar que as políticas públicas precarias exitem exclusivamente no papel, com isso, faz se necessario serem implementadas em carater de urgencia, pois, são os profissionais que aceleram e fazem as coisas acontecerem, no cenário saúde e educação, sem eles, manter o andamento dos serviços é inviavel.

Essas afirmações remetem para a urgencia em se atentarem para as condições da qualidade de vida no trabalho e fora dele. Assim sendo. Novaes, explana que:

a empresa como sendo uma psicoestrutura que implica em diferentes tipos de pessoas, de diferentes niveis, de cuja composição advirão situações diversas que permitirão inferir sobre acontecimentos futuros que, 
Esse é um problema que se arrasta por meio das relações sociais, portanto, nos leva pensar em imbuir essa discussão dentro da proposta curricular, para debater a cerca dessas indagações, bem como, nas diretrizes que nortema a atenção básica, assim sendo, aproximaria as discurssões, mas vale salientar, que as discurssoes não podem se resumir apenas nesses aspectos.

Nesse solo, Sacristán (1995, p.84-85) elucida que: "enqunto um grupo social não vê refletida a sua cultura na escolaridade ou vê refletida menos que a dos outros, estamos simplesmente diante de um probeleme de igualdade de oportunidades".

Taí uma situação que não almejamos, enxugar gelo, nada resolve, precisamos de ações concretas já. Para isso, é necessário que se descarte o ensino organizado de forma fragmentada, que privilegia a memorização de definições e fatos, bem como as soluções padronizadas, o que não atende as exigências dos novos paradigmas. Segundo Pereira e Hannas (2000, p.167-168):

\footnotetext{
A educação não pode se desviar de seu destino, de seu objetivo: o homem e o mundo. A visão não fragmentada do homem corpo, mente e espírito, não pode ser seccionado. A educação não pode se contentar com objetivos limitados, não pode endereçar seus objetivos apenas para situar no mundo material. Somos uma totalidade, então a educação deve voltar-se para a totalidade.
}

Dessa forma, o fazer profissional deve ser realizado de maneira humanizada e com postura ética, seriedade e busca por uma atuação de excelência, organização e desempenho acima do minimamente esperado. As atividades devem ser desenvolvidas de acordo com os planos de cuidado, por meio do qual cada gestor utilizará métodos diferentes de trabalhar.

Portanto, o estudo supõe uma redefinição de competências que possa superar as dicotomias e fragmentações na atenção, superando assim os limites da divisão do trabalho em relação ao tratar e o cuidar.

\subsection{Analisando os dados da pesquisa}

Os profissionais de saúde são humanos sim, sejam eles com suas dificuldades, soluções, aflições, dores, encantos e desencantos, tristezas, alegrias ele chora, adoecem, sofre e morre como qualquer um e por conta desta forma de vivenciar seu 
trabalho está cada vez mais adoecendo e fica cada vez mais nítido de que os profissionais necessitam de cuidados, pois, são humanos tanto quanto, as pessoas que eles cuidam.

Para a estruturação dos sistemas locais de saúde segundo apresentação do secretário de Atenção Básica em 2006, José Temporão.

\begin{abstract}
A atenção Básica considera o sujeito em sua singularidade, na complexidade, na integralidade e na inserção sociocultural e busca a promoção de sua saúde, a prevenção e tratamento de doenças e a redução de danos ou de sofrimentos que possam comprometer suas possibilidades de viver de modo saudável (BRASIL, 2006c, p.10).
\end{abstract}

Assim, compreende-se que há uma preocupação na prevenção de certas doenças que podem ocasionar o servidor, pois entende-se que a consequência do adoecer acaba afetando diretamente a qualidade do exercício das funções e o papel desempenhado pelos professores que sem sombra de dúvidas é realmente insubstituível em qualquer sociedade.

Para Aranha (2006) a educação básica brasileira está em constante transformação desde a Constituição da República de 1988, e para que seja feita uma análise minuciosa desta realidade, é necessário que outras questões, que afetam diretamente a educação, sejam analisadas, tais como a desigualdade social, a economia, a valorização dos profissionais da educação, dentre outras.

Partindo dessa teoria e analisando, mencionamos a Lei de Diretrizes e Bases da Educação Nacional, Lei no 9.394/96, em seu Art. 22 aborda que:

A educação básica tem por finalidade desenvolver o educando, assegurarIhe a formação comum indispensável para o exercício da cidadania e fornecer-lhe meios para progredir no trabalho e em estudos posteriores (BRASIL, 1996).

Para tanto, não tem como negar a importância de cuidar e valorizar o profissional de educação, buscando garantir boas condições de trabalho. Conforme Gadotti (2000), a educação no Brasil está longe de ser uma educação modelo.

Em dezembro de 2019 foi detectado na China a covid 19, uma doença causada pelo corona virus. Em Março de 2020 explodiu a pandemia, momento diferente, delicado, que de certa forma, confima o que ao longo desse texto versamos, que precisa se debruçar sobre os cuidados para com os profissionias de saúde e educação, pois, são eles os colaboradores para diminuir e acabar com a falta de 
informação e formação, e são eles os responsaveis para cuidar dos individuos, porém, para tal, precisam de condiçoes, fisicas, psiquicas, sociais, financeiras, intelectuais para atuar.

No Brasil, os desafios são ainda miores, pois a transmissão da covid 19 se propagou num contexto de grande desigualdade social, e sanitária. Muitas são as formas de contaminação pelo virus, que possui alta taxa de transmissão e um percentual assustador de letalidade. (MOREIRA,SOARES, SANTOS E CRUZ, 2021, p 16).

Vale salientar que a tarefa desses agentes são complexas e em partes conflituosas, onde muitas vezes acarretam doenças psicosomaticas que subitraem a energia desses servidores, razoes suficientes para as autoridades obter um olhar minucioso. Nesse tempo de pandemia, o mudo inteiro, pode perceber a importancia desses operarios, frente ao combate do estado pandemico que o Brasil e o mundo vem atravessando.

Para tanto, cada um além dos conhecimentos cientificos que obtem, tem se reenventado a cada dia, para dar conta de suas atriuições e para além delas, o porque desse desdobramento? Para atender as necessidades apresentadas e porque são humanos acima de tudo, dotados de sentimentos e comprometidos com o que fazem, por se doarem incansavelmente, ja os dá o direito de serem cuidados, memso porque, como cuidar do outro se não estiver bem?

Neste sentido, seria interessante ouvir mais as opiniões dos servidores que atuam diretamente nessa área que, na verdade é quem sofre inteiramente com a falta de acompanhamente e atenção do sistema de saúde. Assim, a compreensão do acompanhamento destes servidores estão relacionadas a um modo de perceber o paciente no contexto dos serviços de saúde.

(...) a força emancipatória na base do SUS só se sustenta quando tomamos como inseparáveis o processo de produção de saúde e o processo de produção de subjetividades protagonistas e autônomas que se engajam na reprodução e/ou na invenção dos modos de cuidar e de gerir os processos de trabalho no campo da saúde. (BENEVIDES e PASSOS, 2005).

Nesse clima, é nescessário convidar todos os gestores a definir diretrizes que assegure os cuidados para com os assalariados da educação e saúde, contribuidores para melhoria de nosso pais e consequentemente do mundo. Entretanto, o que causa inquietude a esses profissionais é a falta de politicas públicas, e de que forma minimizar os impactos causados a esses atores.

A partir dos estudos e vivências durante a trajetória no município de Bom Jesus 
da Lapa - BA, procurei fazer uma releitura do processo educativo construído no decorrer do trabalho com esse público observado, os diálogos mantidos nos momentos informais, nos documentos e nas entrevistas realizadas com os gestores durante a pesquisa promovida pela faculdade.

Nesse sentido, foi percebido que pouco se tem falado sobre o cuidado, atenção e políticas da saúde dos trabalhadores. Por outro lado, hoje, como em qualquer outra área, é possível perceber a existência de um aglomerado de teorias, abordagens e linhas de pensamento que sobreviveram ao longo dos tempos, apesar das críticas, reformulações e aparente extinção da falta de proteção em relação à saúde.

\section{CONSIDERAÇÕES FINAIS}

A temática desenvolvida nesse trabalho, atenção à saúde do profissional de Educação e Saúde, envolve questões amplas que vão desde a operacionalização de um projeto político de saúde calçado em valores como a cidadania, o compromisso social e a saúde como qualidade de vida, passando pela revisão das práticas de gestão tradicionais até os micros espaços de atuação profissional nos quais saberes, poderes e relações interpessoais se fazem presentes.

Chama-se atenção aqui para a necessidade de novos olhares no que tange à saúde dos trabalhadores, especificamente no tocante à análise da atuação desses profissionais que atuam nas modalidades de Saúde e Educação.

No que concerne a isso, o trabalho realizado tem como princípio básico relatar os aspectos importantes e marcantes de uma prática profissional que veio contribuir para a minha formação pessoal e profissional. Durante o desenvolver de nosso estudo, foi possível perceber que a convivência entre a comunidade estudada é bem importante, uma vez que o envolvimento do sujeito no processo de aprendizagem é fundamental para que ele se torne um indivíduo ativo, no intuito de ampliar a responsabilidade pelo próprio conhecimento.

Cabe ao gestor criar situações que levem aos funcionários a interagirem entre si, trabalhando em grupo e buscando informações que possam produzir novos conhecimentos a fim de serem usados ao seu favor.

De modo especifico, pretendeu-se ao longo da pesquisa identificar as causas da inexistência de cuidado e ou acompanhamento com a saúde dos cuidadores (profissionais de saúde e educação); sugerir aos gestores, ações que contemplem e aprimore a atenção e cuidados com a saúde dos profissionais em serviço da saúde e 
educação, a fim de promover a melhoria da qualidade da saúde e a expectativa de vida do trabalhador; e orientar os empregados e empregadores, por meio de ações de educação em saúde, sobre a importância da Saúde, em especial a saúde do trabalhador, além de possibilitar a troca e divulgação de informações entre os trabalhadores, com sua participação nas atividades de prevenção.

Serão necessárias muitas negociações, embates e mudanças estruturais e sociais, assim como construção de redes sociais que compartilhem a construção de novas práticas que possam dar visibilidade à novas formas de construção de saúde e de vida.

Por fim, é nescessario promover a melhoria da qualidade da saúde e a expectativa de vida do trabalhador; e orientar os empregados e empregadores, por meio de ações de educação em saúde, sobre a importância da Saúde, em especial a saúde do trabalhador, além de possibilitar a troca e divulgação de informações entre os trabalhadores, com sua participação nas atividades de prevenção. 


\section{REFERÊNCIAS}

ARANHA, M. L. A. História da educação e da pedagogia: geral e Brasil. 3. ed. rev. e ampl. São Paulo: Moderna, 2006.

BRASIL. Ministério da Saúde. Secretaria de Atenção à Saúde. Departamento de Atenção Básica. Política nacional de atenção básica. Brasília: Ministério da Saúde, 2006.

BENEVIDES, Regina e PASSOS, Eduardo. A humanização como dimensão pública das políticas de saúde. Ciência e Saúde Coletiva. V.10 n.3 RJ: jul/set. 2005.

BRANDÃO, José Carlos. O que é educação? 33. ed. São Paulo: Brasiliense, 1995. (Coleção Primeiros Passos).

MATOS.Elizete.Lúcia.Moreira. MUGIATTI. Margarida. Maria. Teixeira de Feritas.Pedagogia Hospitalar: A humanização Integrando educação e saúde.4.ed- Petrópolis,RJ:Vozes,2009.

MOREIRA. Antonio.Domingos.SOARES. Jamile de Souza. SANTOS.Arlete Ramos dos.CRUZ.Queziane Martins da.Trilhas na Educação.Santo Ângelo,Brasil, Metrics,2021.

NOVAES.M.Helena. Psicologia da educação e Prática Profissional. Petrópolis, RJ: Vozes,1992,

PEREIRA, I. L. L.; HANNAS, M. L. Educação com Consciência: fundamentos para uma nova abordagem pedagógica. São Paulo: Gente, 2000. (Coleção Novos Rumos para a Educação: v1).

SACRISTAN.J.Gimeno. Curriculo e diversidade Cultural.In Silva, Tamaz Tadeu da; Moreira,A.F.(orgs).Petrópolis,RJ:Vozes, 1995. 